\title{
Comunidade de prática em terapia ocupacional: a avaliaçáo do processo pelos participantes e pelos pesquisadores
}

\author{
Sandra Maria Galheigo ${ }^{a}$, Claudia Pellegrini Braga ${ }^{a}$, Fernanda Stella Risseto Mieto ${ }^{a}$, \\ Fernanda Viotti Parreira ${ }^{b}$, Gabrielle Quintiliano Sarmento ${ }^{a}$, Margareth Motta ${ }^{c}$, \\ Mariane Campopiano Abraháo Silva ${ }^{d}$, Mirella Ferreira Santos ${ }^{a}$, Priscilla Feres Spinola ${ }^{e}$, \\ Raquel Lima, Rosa Maria de Araújo Mitreg, Thais dos Reis Olher Lagôa ${ }^{\mathrm{h}}$, \\ Thelma Almir Oliveirai, Walkyria de Almeida Santos ${ }^{j}$
}

\author{
aDepartamento de Fisioterapia, Fonoaudiologia e Terapia Ocupacional, Faculdade de Medicina, Universidade de \\ São Paulo - USP, São Paulo, SP, Brasil. \\ 'Escuela de Terapia Ocupacional, Universidad Central de Chile, Santiago, Chile. \\ 'Hospital de Aeronáutica de São Paulo, São Paulo, SP, Brasil. \\ dUniversidade Federal de São Carlos - UFSCar, São Carlos, SP, Brasil. \\ ${ }^{e}$ Centro Hospitalar do Sistema Penitenciário do Estado de São Paulo, São Paulo, SP, Brasil. \\ ${ }_{\mathrm{f} C A P S}$ Infantil Perus, São Paulo, SP, Brasil. \\ gInstituto Nacional de Saúde da Criança, da Mulher e do Adolescente Fernandes Figueira, Fundação Oswaldo \\ Cruz - Fiocruz, Rio de Janeiro, RJ, Brasil.

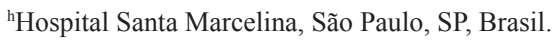 \\ ${ }^{i}$ Centro Universitário São Camilo, Hospital Geral de Carapicuíba, São Paulo, SP, Brasil. \\ JInstituto de Oncologia Pediátrica - GRAACC, São Paulo, SP, Brasil.
}

\begin{abstract}
Resumo: Este artigo apresenta resultados de pesquisa-ação com terapeutas ocupacionais em uma comunidade de prática, cujo objetivo foi discutir a produção de cuidado oferecida pela terapia ocupacional a crianças e adolescentes hospitalizados. Participaram da pesquisa nove terapeutas ocupacionais de hospitais da cidade de São Paulo. Foram realizados dez encontros presenciais e atividades virtuais disponibilizadas em um ambiente computacional mediado pela Web. Os encontros presenciais foram gravados e filmados. Este artigo tem como objetivo apresentar a avaliação que as participantes e pesquisadoras fizeram do processo vivido na comunidade. Por meio de análise de conteúdo, foram identificadas 17 unidades de registro, agrupadas em quatro temáticas principais: processo dialógico; implicações teórico-práticas; processo reflexivo; processo participativo e suas barreiras. A avaliação do processo mostrou que o diálogo durante os encontros colaborou para o senso de pertencimento, integração e consciência/coesão grupal, e possibilitou a discussão e a reflexão de temas relevantes sobre a prática do terapeuta ocupacional. A comunicação direta mostrou-se como a principal forma de trocas profissionais neste grupo. As condições de trabalho dos participantes, a dificuldade de acesso a computadores e ambientes de trocas virtuais, sobretrabalho gerado pelos encontros e o deslocamento nos grandes centros urbanos foram fatores complicadores para uma maior adesão dos participantes. A avaliação mostrou que essa estratégia favoreceu a construção compartilhada de saberes e que sua implementação pode fomentar a reflexão, o desenvolvimento da pesquisa e a produção de conhecimento, bem como contribuir para o aprimoramento da prática profissional do terapeuta ocupacional.
\end{abstract}

Palavras-chave: Terapia Ocupacional, Conhecimento, Prática Profissional.

Autor para correspondência: Sandra Maria Galheigo, Centro de Docência e Pesquisa em Terapia Ocupacional da Faculdade de Medicina da Universidade de São Paulo, Rua Cipotânea, 51, Cidade Universitária, CEP 05508-900, São Paulo, SP, Brasil, e-mail: sandramg@usp.br Recebido em Set. 26, 2013; $1^{\text {a }}$ Revisão em Fev. 18, 2014; 2 ${ }^{\text {a }}$ Revisão em Mar. 19, 2014; Aceito em Mar. $31,2014$. 


\title{
Occupational therapy practice community: process evaluation by the participants and researchers
}

\begin{abstract}
This article presents the results of a participatory action research with occupational therapists in a community of practice which purpose was to discuss the care production provided by occupational therapy to hospitalized children and adolescents. The participants were nine occupational therapists from hospitals of the city of São Paulo. Ten face-to-face meetings were conducted and a Web-mediated environment was created for conducting virtual activities. The face meetings were recorded and tapped. This article aims to present the evaluation made by the participants and researchers about the process experienced in the community. Through content analysis, seventeen reporting units were identified and grouped into four main themes: the dialogic process; theoretical and practical implications; reflective process; participatory process and its barriers. The process evaluation showed that dialogue during the meetings contributed to a sense of belonging, integration, and awareness/group cohesion and made possible discussing and reflecting on topics relevant to the practice of occupational therapist. Direct communication proved to be the main form of exchange among the professionals in the group. The participants working conditions, the computers and virtual environments access issues, the surplus work generated by meetings and the displacement in urban centers were complicating factors for the participant's greater adhesion. Evaluation showed that this strategy favored the construction of shared knowledge, and its implementation can foster reflection, research development and knowledge production, as well as contribute to the occupational therapist professional practice improvement.
\end{abstract}

Keywords: Occupational Therapy, Knowledge, Professional Practice.

\section{Introdução}

No processo de produção de saberes e práticas profissionais, o dinamismo de um campo é dado pela qualidade da interatividade entre a pesquisa, a educação (graduada, continuada e pós-graduada) e os cenários de prática. Destaca-se também a efetividade da divulgação de conhecimentos na comunidade profissional, seja através da publicação em periódicos ou da apresentação em eventos científicos. Nesse contexto, a terapia ocupacional brasileira - enquanto núcleo profissional que transita por um conjunto de campos de saberes e práticas - teve sua produção e divulgação científica e tecnológica alavancadas, embora com variaçôes importantes nos diferentes campos de saber e prática, a partir dos anos 1990, quando da criação dos primeiros periódicos brasileiros de terapia ocupacional (GALHEIGO; ANTUNES, 2008). Especificamente, a produção da terapia ocupacional em contextos hospitalares apresenta um desenvolvimento mais recente, se contarmos que a maior parte da produção científica aconteceu após 2000 (GALHEIGO; ANTUNES, 2008). De fato, é ao final dos anos 2000 que começa a acontecer um conjunto de iniciativas para a organização dos profissionais que trabalham na área hospitalar, tais como um grupo de discussão virtual - Grupo Nacional de Terapia Ocupacional em Contextos Hospitalares - e a organização de simpósios regionais e nacionais, sediados nos congressos brasileiros de terapia ocupacional. Mais recentemente, em agosto de 2012, constitui-se a Associação Científica de Terapia Ocupacional em Contextos Hospitalares e Cuidados Paliativos (ATOHOSP), que visa a reunir, científica e culturalmente, terapeutas ocupacionais que atuam em contextos hospitalares e/ou em cuidados paliativos, de forma a promover o desenvolvimento técnico- científico e divulgar o papel do terapeuta ocupacional na área (ASSOCIAÇÃO..., 2013). Como resultado desse processo, nos últimos três anos, em consulta às revistas nacionais de terapia ocupacional, percebe-se um significativo incremento na produção científica em contextos hospitalares, que, no entanto, ainda carece de maiores estudos que dimensionem sua relevância e impacto.

Há expectativas que essas mudanças recentes colaborem, em médio prazo, para a consolidação do campo, de forma a garantir maior incorporaçáo de profissionais em contextos hospitalares, melhoria das condiçóes de trabalho e ampliação do reconhecimento profissional pelos membros $\mathrm{da}$ equipe de saúde. Não obstante, o cenário atual ainda remete a uma realidade em que os profissionais em geral se sentem pouco reconhecidos por seus pares e pela equipe multiprofissional, e que se representa economicamente por salários inferiores aos demais campos profissionais, além de parcas condiçōes físicas, materiais e de recursos humanos (GALHEIGO, 2006; GALHEIGO; TESSUTO, 2010).

Em pesquisa realizada em 2009 (GALHEIGO, 2009), identificou-se uma peculiaridade intrínseca ao ato de explicar a açáo da terapia ocupacional em 
contextos hospitalares. A maioria dos entrevistados valia-se de narrativas clínicas para apresentarem seu trabalho, com visível desconforto para a explicitação das bases teórico-metodológicas, o que remetia a claras tensôes epistemológicas do campo. Os participantes também apontaram cisões - teoriaprática, academia-assistência - produzidas desde os cursos de graduação, considerando que o ensino pouco dialoga com a prática profissional cotidiana (GALHEIGO, 2009).

Nesse cenário é que foi identificada a necessidade de estratégias para se lidar com a questão profissional do 'saber dizer o que faz' e 'saber justificar por que faz'. Esta constatação é corroborada por outros pesquisadores (WILDING; WHITEFORD, 2007; KINSELLA; WHITEFORD, 2009), que vêm assinalando a importância de se promover a reflexão do terapeuta ocupacional em relação à sua prática e às formas de falar sobre o assunto. Para Kinsella e Whiteford (2009), um recurso para a terapia ocupacional avançar, no sentido de uma maior reflexáo sobre sua prática profissional, seria o de utilizar formas de aproximação dos profissionais, tais como as comunidades de prática. Estas teriam o objetivo de proporcionar o fomento da 'reflexividade epistêmica' tal como pensada por Bourdieu e Wacquant (1992). Para esses autores, a reflexividade epistêmica é um mecanismo importante para o desenvolvimento de um campo de conhecimento que, ao refletir sobre suas origens e bases epistemológicas, pode aprofundá-las e, em consequência, ganhar legitimidade.

Wenger, McDermont e Snyder (2002, p.4) conceituam comunidades de prática como "[...] grupos de pessoas que compartilham uma preocupação, um conjunto de problemas, uma paixáo por determinado assunto, e que aprofundam seu conhecimento na área ao interagir regularmente". Comunidades de prática podem ser utilizadas como estratégias para aprendizagem, educaçáo continuada e fomento à troca de experiências em serviço, deixando de ser puramente espontâneas e passando a ser estimuladas. Desde meados de 2000, começaram a ser utilizadas em terapia ocupacional como uma ponte de colaboraçáo universidade-serviço (knowledgetranslation) (CHAU; MOGHIMI; POPOVIC, 2013; CRAMM; WHITE; KRUPA, 2013), no ensino prático (DERDALL; MULHOLLAND; BROWN, 2010; LIDSKOG; LÖFMARK; AHLSTRÖM, 2009) e em pesquisas para a promoção da reflexão sobre a prática profissional (WILDING; CURTIN; WHITEFORD, 2012; GALVIN; WILDING; WHITEFORD, 2011; HOFFMANN; DESHA; VERRALL, 2011; WIMPENNY et al., 2010; WILDING; WHITEFORD, 2007, 2009).
Para Wenger (1998), que cunhou o termo, todos nós pertencemos a comunidades de prática; estas são parte integrante de nossas vidas e, portanto, embora pareça uma novidade conceitual, a experiência nos mostra o contrário. Cotidianamente, participamos informalmente em várias dessas comunidades, umas de modo mais central, outras de forma mais periférica.

Baseando-se na concepção de Habermas de esfera pública, Kemmis (2005, p.394) concebe que uma comunidade se articula como um espaço comunicativo "[...] em que as pessoas podem conversar abertamente, livremente, criticamente e autocriticamente sobre a natureza, o significado e as consequências do que fazem". Assim, ele defende a construção compartilhada do saber na comunidade como um dos recursos para a construção de práticas participativas, colaborativas e transformadoras, de forma a poderem produzir solidariedade e construir legitimidade. Dado que transformar práticas e produzir saberes num determinado domínio implica em estabelecer um diálogo crítico com as dimensôes sociais, discursivas e históricas, nas quais os saberes e práticas estão imersos, considera-se que as práticas poderiam ser mais bem desenvolvidas de forma coletiva, através de comunidades de prática (KEMMIS, 2005; KINSELLA; WHITEFORD, 2009).

A partir destes pressupostos, no período de 2011 a 2013, foi constituída uma comunidade de prática para discutir a produção de cuidado oferecida pela terapia ocupacional a crianças e adolescentes hospitalizados. A expectativa inicial era a de que, por meio de um grupo de discussão, isto é, ao submeter à reflexão a prática cotidiana, a conscientização daquilo que acontece de forma tácita durante a ação profissional poderia adquirir novo sentido. Assim, fomentar o interesse e a experiência de terapeutas ocupacionais pelas discussóes de ordem reflexiva e epistemológica poderia contribuir para a compreensão ampliada sobre a sua prática e para a afirmação de seu papel profissional no hospital.

A pesquisa teve, assim, dois objetivos principais: (i) implementar uma comunidade de prática e avaliar sua exequibilidade como recurso para a realização de trocas e para a produção de conhecimento entre terapeutas ocupacionais e (ii) produzir debate e conhecimento sobre as características da atenção e as abordagens utilizadas por terapeutas ocupacionais junto a crianças e adolescentes hospitalizados.

No início da pesquisa, um acordo foi estabelecido entre pesquisadores e participantes em relação à autoria da publicação dos resultados da pesquisa: os pesquisadores seriam os autores dos artigos que remetem ao primeiro objetivo da pesquisa e as participantes seriam coautoras dos resultados referentes ao segundo objetivo, desde que se sentissem à vontade 
em revelar suas identidades. Para a clareza de papéis, neste artigo, usamos o termo pesquisadoras para as pesquisadoras formais, idealizadoras e executoras da pesquisa, e participantes para os pesquisadoresparticipantes que foram convidados para o projeto, já que a pesquisa-ação considera como pesquisadores todos os que nela participam.

Este artigo tem como objetivo apresentar a avaliaçáo que as participantes e pesquisadoras fizeram do processo vivido na comunidade durante sete meses e é assinado pelo conjunto dos membros da comunidade.

\section{Métodos}

A abordagem metodológica utilizada foi a da pesquisa-ação, para a qual foi constituída uma comunidade de prática com 13 membros: duas pesquisadoras formais, que elaboraram o projeto, o submeteram ao Comitê de Ética, obtiveram fundos de pesquisa para sua realização, organizaram as atividades de pesquisa e a análise do material produzido; nove participantes-pesquisadoras, que aceitaram o convite e se engajaram nas atividades propostas; duas estudantes bolsistas de pesquisa, que realizaram o apoio à pesquisa e participaram dos encontros da comunidade. A realizaçáo do projeto contou ainda com três consultoras de pesquisa: uma nacional, que colaborou nas discussóes e participou de atividades durante o percurso da comunidade, e duas internacionais, que colaboraram com os aspectos teóricos e conceituais da pesquisa.

As pesquisadoras-participantes eram terapeutas ocupacionais de hospitais da cidade de São Paulo, que trabalhavam, de forma constante ou eventual, em unidades pediátricas ou em unidades de adultos que atendessem adolescentes. Foram identificadas após realização de levantamento de profissionais em hospitais no município e selecionadas de modo a garantir heterogeneidade de experiência profissional e local de trabalho. Uma participante se voluntariou a integrar a comunidade, após informação de um de seus membros. Todas pertencentes ao sexo feminino, com faixa etária compreendida entre 20 e 59 anos, assim distribuídas: uma acima dos 50 anos; uma entre 40 e 49 anos; quatro entre 30 e 39 anos, e três entre 20 e 29 anos. Quatro participantes tinham até 5 anos de formadas; três, de 5 a 10 anos, e duas, entre 25 e 30 anos de formadas.

A comunidade se reuniu por sete meses, durante os quais foram realizados dez encontros presenciais e encontros/atividades virtuais, em um ambiente computacional mediado pela Web, ao qual todos os membros tiveram acesso e preparaçáo para uso.
O ambiente computacional possibilitou a disponibilização e a troca de material bibliográfico e biográfico, a participação em fóruns, blogs e chats, e tinha a intençáo de sustentar a comunidade entre os encontros presenciais, possibilitando a construção social e dialogada do conhecimento, e permitindo aos participantes um papel ativo que garantisse sua progressiva autonomia no processo de compartilhamento e reflexão de suas experiências.

Os encontros presenciais foram gravados e filmados. A transcrição destes e o material produzido virtualmente foram transformados em documentos, tendo ambos sido processados por análise de conteúdo sob a perspectiva hermenêutica-crítica (MINAYO, 2002), principal norteador metodológico na realização deste estudo. Para essa autora, a combinação da hermenêutica e a dialética possibilita que a compreensão e a crítica sejam articuladas. Assim, pelo processo interpretativo, buscou-se aprender o significado manifesto nos textos e nos discursos dos participantes, bem como o processo de intersubjetividade que se estabeleceu na consecução da comunidade de prática. Já por meio da perspectiva dialética, buscou-se apreender o dissenso e a influência dos macroprocessos, fazendo com que o material produzido fosse criticamente estudado.

É importante salientar que a realização de uma pesquisa-ação implica em um recrutamento de sujeitos de pesquisa sensivelmente interessados em participar. Assim, a problemática a ser trabalhada na comunidade de prática tinha de ser uma preocupação comum, impregnada de sentido para os participantes. Indo além, como afirma Thiollent (1987, p.93), “[...] a pesquisa-ação é uma pesquisa centrada na questão do agir" e, assim, implicou em um compromisso constante das participantes sobre o seu plano de ação, vislumbrando um futuro juntos, que começou a acontecer quando a comunidade entrou em prática. Um roteiro de temas foi consensuado no início das atividades da comunidade, mas havia flexibilidade de mudança temática conforme decisão tomada ao final de cada encontro presencial. As temáticas versaram sobre avaliaçáo e levantamento de necessidades da população hospitalizada, a produção de cuidado realizada pela terapia ocupacional, o papel da atividade lúdica, o acompanhamento familiar, a construção do vínculo e o enfrentamento de situaçôes complexas.

A temática do décimo e último encontro presencial foi a avaliação do processo vivido e teve um tratamento de dados exclusivo. Por meio de análise de conteúdo, recortamos fragmentos do discurso das participantes e os agrupamos, conforme seus sentidos, em 17 unidades de registro que, após releitura, foram agrupadas em quatro temáticas principais: processo dialógico; implicaçôes teórico-práticas; processo 
Tabela 1. Temas e suas unidades de registro do Encontro Presencial no 10.

\begin{tabular}{ll}
\hline \multicolumn{1}{c}{ TEMAS } & \multicolumn{1}{c}{ UNIDADES DE REGISTRO } \\
\hline O processo reflexivo & Reflexão intencional \\
& Reflexão narrativa \\
O processo dialógico & Reflexão crítica \\
& Espaço de escuta e troca \\
& Identidade \\
& Pertencimento \\
& Integração \\
& Consciência e coesão grupal \\
& Lidar com a diferença \\
Implicações teórico-práticas & Autoconhecimento \\
& Crescimento \\
& Sentidos da experiência \\
& Ruptura teoria-prática/academia-prática \\
O processo participativo e os “atravessamentos" & Participação grupal \\
& Satisfação em participar \\
& Compromisso \\
& 'Atravessamentos' \\
\hline
\end{tabular}

reflexivo; processo participativo e suas barreiras (Tabela 1). Para cada temática, foi construído um quadro composto de suas unidades de registro e dos fragmentos dos discursos dos participantes no grupo, conforme o exemplo no Tabela 2. Estes serviram de base para a organizaçáo dos resultados aqui apresentados. A leitura final de cada temática revelou que a dialogia e a interconectividade dos discursos dos participantes deveriam ser destacadas, já que mais do que explicitar uma posição individual, falavam de um coletivo - uma comunidade de prática. Portanto, para evitar sua fragmentaçáo, optamos por apresentar e discutir os resultados articulados em discursos-síntese, nem sempre concisos, que elucidam determinada temática a partir da perspectiva de uma comunidade, um único sujeito discursivo, polissêmico e polifônico ${ }^{1}$.

A avaliação das pesquisadoras sobre a experiência da comunidade também tomou como base a análise dos processos vividos ao longo da pesquisa.

\section{Resultados e discussão}

\subsection{O processo reflexivo e dialógico de uma comunidade de prática segundo as participantes}

\subsubsection{Sobre o processo dialógico na comunidade de prática}

\subsubsection{Espaço de escuta e troca}

Diálogo e cooperação foram os aspectos mais valorizados pelos participantes ao longo da pesquisa, o que remete a resultados de pesquisa anterior (GALHEIGO; TESSUTO, 2010), que salienta a sensação de isolamento que o terapeuta ocupacional vivencia no trabalho no hospital. O processo dialógico, que a discussão grupal propicia, apareceu como um elemento central para a produção de sentido sobre o processo vivido. Ficou evidente o interesse das participantes pelo diálogo em tempo real, seja nas atividades presenciais ou virtuais, sendo que, nestas, o chat foi o recurso mais utilizado, deixando o fórum, o compartilhamento de arquivos, o blog e o diário em clara desvantagem.

A aderência à comunidade se refletia na possibilidade de se ter um espaço de escuta e troca, um espaço de cooperação. Compartilhar histórias sobre a prática profissional servia de base para o processo reflexivo, assim como o resgate da palavra.

A comunidade de prática possibilitou um espaço
de troca epertencimento. A possibilidade de estar
com vocês, de compartilhar, escutar o outro reporta
a cenas de atendimentos meus. Assim, ouvir as
experiências clinicas dos outros me permitia fazer
reflexão do meu próprio trabalho, do meu dia-
a-dia independente de qual população estivesse
atendendo, seja criança, adulto ou idoso. O espaço
de reflexão é um espaço de vivência, importante
para levar à ação. Teve consolo, os cursos, as falas;
colocamos coisas em prática, a gente discutiu o
dia-a-dia operando com a palavra, o que é muito
importante.

Havia uma intensidade implícita no processo de discussáo sobre a prática profissional junto aos seus próprios pares, que mobilizava os próprios fazeres e saberes, mas que também trazia uma retroalimentação que acontecia a partir da experiência do outro. Indo além, a vivência possibilitava um resgate do valor do próprio trabalho e da terapia ocupacional.

Foi um processo que trazia questóes: Ai, meu Deus, o que en vou falar aqui? Que medo de falar 
Tabela 2. Unidades de registro e processo dialógico, com extratos dos discursos dos participantes.

TEMA PROCESSO DIALÓGICO

Unidades de registro
Espaço de escuta $\mathrm{e}$ troca

Identidade

Pertencimento

Integração

Consciência e coesão grupal

Lidar com a diferença

\section{Extratos dos discursos dos participantes}

"esse espaço de troca, de um pertencimento, estar com vocês, que eu compartilho, que eu escuto outro, porque ao mesmo tempo eu escuto o outro como alguém e vai vindo cenas de atendimentos meus, e eu vou tentando significar tudo isso...(P5) "você faz um encontro... dá um animo - "Ah, deixa ir atrás, eu vou buscar, olha ela falou isso, deixa eu conhecer..." (P9)

"foi um espaço de reflexão de uma palavra que eu acho que é vivência, ter condições de fazer um espaço de vivência mesmo, consolo, teve os cursos, teve as falas, a gente colocou coisas em prática, a gente discutiu o dia-a-dia aqui, é um espaço de vivência muito importante para levar a ação. Mas a situação dos grupos para mim assim, operando com a palavra é muito importante" (P1)

"Então muitas vezes desse compartilhar, desse escutar o outro, escutar outras TOs fazendo terapia ocupacional, isso ia fazendo com que eu falasse - que legal ser TO - e eu acho que isso é algo muito ligado à identidade" (P5)

"identidade do vir a ser, para mim eu acho que a modificação que isso me trouxe..." (P2)

"eu acho que a gente refletiu muito sobre isso... caminhos assim que foram e estão sendo construídos, dentro da nossa prática profissional... os espaços que a gente está, o que tem a ver com identidade." (P1)

"Eu lembro, desde o primeiro dia, que a gente falou do hospital, a chegada do hospital (...), acho que foi o que mais me tirou angústia, (...) acho que saímos daqui todas mobilizadas porque a gente tinha um fazer em comum, percursos, caminhos diferentes, formações diferentes, tempo de formada diferente, mas todo mundo tem uma coisa em comum." (P1).

"acho que isso foi uma coisa boa para o grupo, esse pertencer, esse buscar uma identidade comum de todo mundo para nossa prática profissional, com o enfoque no hospital." (P1)

“tudo provocou uma modificação, até de pertencimento..." (P2)

"eu não me senti tão pertencente ao grupo, mas, ao mesmo tempo, eu estava vendo o que estava acontecendo, e me fez muita falta de não estar aqui" (P9)

"acho que isso foi uma coisa boa para o grupo, esse pertencer." (P1)

"eu não me sinto menos pertencente por não ter vindo a algumas reuniões" (P5)

"é muito difícil, muito puxada a vida profissional, e acho que o grupo era um espaço um tanto de integrar, algumas coisas, foi muito integrador." (P4)

" consciência da construção... coletiva, que sugere uma bagagem de alguma forma, que é pessoal mas é do grupo" (P2)

"Acho que uma palavra que pode ser colocado para este grupo é persistência, acho que esse grupo conseguiu se manter nesse formato aqui sem ser de alunos" (P9)

"Foi muito ousada porque nós estamos todas contentes por sermos diferentes, [termos] experiências muito diferentes" (P4)

"no começo também tinha uma coisa de como afinar as linguagens, às vezes cada um estava falando de um lugar diferente (...) Será que ela entende do que eu vou estar falando? Então, às vezes, eu tinha um estranhamento" (P4) alguma coisa! Tem pessoas muito mais experientes. Nossa, como que vai ser esse trocar, tem gente que quer ouvir, como eu vou falar? Fui tentando significar tudo isso. Edeu um ânimo-Ah, deixa eu ir atrás, eu vou buscar. Olha! Ela falou isso, deixa eu conhecer. Isso ia fazendo com que eu falasse - Que legal ser TO! - e eu acho que isso é algo muito ligado à identidade - a identidade do vir-a-ser.

\subsubsection{Identidade, pertencimento e o lidar com a diferença}

A comunidade de prática resultou em um microcosmo profissional que colocava em cena a questão da identidade profissional - mostrava-se algo em comum entre terapeutas ocupacionais que trabalham em contextos hospitalares. Interessante notar, entretanto, que o diálogo entre 'identidade' e 'diferença' se colocou não como um antagonismo 
de saberes e fazeres, de tendências epistemológicas possivelmente contraditórias, mas como uma "identidade feita de diferenças", para utilizar a expressão de Lima (1999, 2003). Ao mesmo tempo, a comunidade revelou uma ausência - uma falta de lugar onde os trabalhos em contextos hospitalares podem ganhar maior explicitação e ser reconhecidos com clareza pelo coletivo.

Discutir sobre os caminhos que foram construidos e que estão sendo construídos, dentro da nossa prática tem a ver com identidade, pois por mais que a gente tenha a nossa identidade profissional dentro da gente, o tempo todo a reconstruimos, concretizamos. Eu lembro, desde o primeiro dia, que a gente falou do hospital, a chegada do hospital, saimos mobilizadas porque a gente tinha um fazer em comum. Percursos, caminhos diferentes, formaçóes diferentes, tempo de formada diferente, mas todo mundo tem uma coisa em comum. Nós estamos todas contentes por sermos diferentes, termos experiências muito diferentes. No começo também tinha uma coisa de como afinar as linguagens, às vezes cada um estava falando de um lugar diferente e me perguntava: Será que ela entende do que eu estou falando? Então, às vezes, havia estranhamento. No grupo de comunidade que participei na especialização, nós éramos as seis do mesmo lugar, todo mundo sabia de que serviço se tratava, tinha os mesmos objetivos e questōes institucionais. Mas, aqui não. De que lugar essas pessoas estäo falando? Em que instituição que ela trabalha? Que população ela atende? Onde en vou compartilhar, o que eu posso trazer, o que daqui en levo?

A criação de uma comunidade também remeteu à falta de lugares que garantissem o senso de pertencimento de um coletivo. A possibilidade de a comunidade de prática prover esse lugar de pertencimento, mesmo que transitório, mesmo que não completamente aproveitado, ganhou, portanto, destaque especial.

Acho que isso foi uma coisa boa para o grupo, esse pertencer, esse buscar uma identidade comum de todo mundo para nossa prática profissional, com o enfoque no hospital. Acho que a produção de sentido vem disso tudo, de refletir sobre identidade, do que é preciso, do que é buscar pertencer a um grupo. Fiquei pensando um pouco do meu processo no grupo, do meu pertencimento; e acho que foi uma proposta muito ousada. Teve momentos de estranhamento, ao mesmo tempo acho que eu fui, sim, em muitos momentos me sentindo pertencendo. Mesmo não vindo a algumas reuniōes, eu não me sinto menos pertencente. Mesmo eu não me sentindo tão pertencente ao grupo, eu estava vendo o que estava acontecendo, e me fez muita falta quando não estava aqui. Acho que isso foi uma coisa boa para o grupo, esse pertencer.

\subsubsection{Integração, consciência e coesão grupal}

A existência e a sustentação de um espaço de encontro e diálogo que fosse livre e horizontal vieram a explicitar as adversas condições de trabalho do terapeuta ocupacional. Frente às condiçôes desintegradoras da prática cotidiana referidas pelas participantes, a comunidade mostrou-se uma experiência de promoção de integração da profissional consigo mesma, de consciência e de coesão grupal. Afinal, sustentar um espaço de diálogo e cooperação, que não fosse formatado por qualquer tipo de proposta e exigência acadêmica, que envolvesse corresponsabilidade e autonomia, era ousado e exigia persistência.

Afinal, é muito difícil, muito puxada a vida profissional, e acho que o grupo era um espaço e tanto de integrar. É uma profissäo que eu acho maravilhosa, eu sou apaixonada, mas é dificil ser TO; a gente ganha pouco, exige-se muito. Acho que quando eu estava aqui era muito integrador. Possibilitou-me a consciência da construção coletiva, que sugere uma bagagem de alguma forma, que é pessoal, mas é do grupo. Fui me implicando muito com ele, acho que foi um espaço muito importante para mim. Ao mesmo tempo, foi um espaço de corresponsabilidade mesmo. Quando nosso trabalho para o Congresso foi aprovado, senti aquele compromisso de que esse grupo tinha que produzir alguma coisa que não é só de vocês, pesquisadores. Acho que uma palavra que pode ser colocada para este grupo é persistência, acho que esse grupo conseguiu se manter nesse formato aqui, sem ser de alunos, e eu espero que não termine.

\subsubsection{As implicações teórico-práticas}

As aproximaçóes universidade e serviços, atividade acadêmica e prática profissional, trouxeram um entorno delicado de discussóes que se constituíram no processo de divisão trabalho intelectual-trabalho manual. Esta tem sido uma dicotomia difícil de ser superada e que apareceu espontaneamente como um divisor de águas entre as pesquisadoras e as participantes. Se falar da própria prática remetia a retomar suas próprias origens profissionais e compromissos com a terapia ocupacional, permitia também dar visibilidade à dificuldade de atualizaçáo dada a ausência de programas de educação permanente 
para os terapeutas ocupacionais em geral, mas, para os que trabalham em hospitais, de forma mais evidente.

Em relação à prática profissional também, assim, fez muito sentido na prática, me fez, assim, me sentir aumentada. As discussöes me possibilitaram tomar consciência cada vez mais da minha origem profissional e ampliar minha consciência de responsabilidade sobre minha profissão. Eu estou tão fechada - a gente sai da faculdade, da parte cientifica e ai parece que você perde isso, toda a maneira acadêmica [que] tem uma coisa de discussão, de buscar texto e não sei o quê. E quando você fica só na prática você se isola um pouco, você não fica sabendo o que está acontecendo. Quando se faz esse trabalho sozinho, às vezes você acaba entrando em um marasmo, mesmice. No início eu falei - Vai ser ótimo, vou me atualizar! Ainda quando vinham os textos, eu falava - Ai que bom, não perdi! - retomar, coisa que com a prática, você vai levando ou fica só naquilo que você está acostumado a ver no dia a dia. A academia é isso, quem náo a quer, fica meio separado. Mas não, tem que ter a união. Tem que ter uma união e uma troca constante.

Além da ausência de programas de educação permanente, a criaçáo de uma comunidade de prática evidenciou a falta de espaços de troca, fóruns de discussão, o que vem, novamente, retomar a questáo do isolamento profissional como um obstáculo para o desenvolvimento da terapia ocupacional.

Dava esse 'up' assim de você ficar pensando, da prática profissional também, poder ouvir, poder discutir sobre cuidado, sobre a questão da família e poder ouvir os processos terapêuticos que cada terapeuta ia contando aqui. Isso é riquissimo demais, e evidentemente isso vai trazer uma prática profissional muito mais consciente, muito mais cuidadosa. Também, quando você está na faculdade, você vai lendo os textos, você vai tendo só as aulas teóricas, mas e a prática? Mas, e o estar junto com as pessoas trocando? Um grupo como esse, todos os terapeutas ocupacionais deveriam participar, porque é extremamente enriquecedor, e extremamente modificador também, você não entra da mesma forma como você sai.

\subsubsection{O processo reflexivo}

Em sua avaliação final, o grupo não se deteve a aprofundar como os processos reflexivos aconteceram no processo da comunidade de prática. Estes processos foram mencionados por alguns participantes, mas foi evidente que esta discussão não se constituiu em uma temática importante para o grupo. Possivelmente, a preocupaçáo com os processos reflexivos tenha sido prioritariamente acadêmica, dos pesquisadores. A menção ao processo reflexivo apareceu apenas como um elemento decorrente do processo.

Eu acho que a gente conseguiu refletir aqui sobre a percepção de caminhos; caminhos assim que foram construidos e que estão sendo construidos. Foram importantes as trocas, ouvir o trabalho, as experiências clinicas dos outros; o quanto isso permitia fazer reflexão do seu trabalho. Eu estou muito crítica com todas essas questōes, reflexão...

\subsubsection{O processo participativo e seus 'atravessamentos'}

Em relação à participação, o grupo evocou suas diferenças e desejos por uma maior presença face a face. O termo 'atravessamentos', usado pelas participantes no encontro, remetia a barreiras, obstáculos, impedimentos e problemas que 'atravessaram' o percurso grupal; entretanto, parecia que sua utilização buscava dar um tom menor que esses outros termos poderiam insinuar.

Eu pude participar pouco, mas participei. Podia dar vazão, de repente a gente estava junto e não era uma coisa que ficava certinho, foi potencial. Era importante a presença, você olha e vê que não está sozinha. Algumas coisas foram muito legais, mas acho que faltou a participação do grupo todo, acho que ia ser muito mais rica; você vai ficando mais à vontade com as pessoas, e criando outra possibilidade de estar junto, de se colocar. Foi bom vocês, pesquisadoras, estarem junto, fazerem todas as coisas, de vocês também participarem das discussóes, não ficarmos apenas nós falando, que ai sim a gente ia se sentir objeto da pesquisa e não participante da pesquisa. Eu espero que o grupo não termine, eu acho que vocês têm que propor mais coisas porque acho que tem mais coisas ainda para a gente produzir juntos. Quem sabe, esse grupo possa continuar aí de outras formas.

Em relação aos 'atravessamentos' que limitaram a participação, o grupo novamente expressou suas diferenças e desejos por um maior compromisso.

Vocês preparam uma coisa para a gente, e tem um compromisso com os profissionais, todo mundo sabia que iriam ser dez encontros, que iriam ser nesse horário, eventualmente, lógico, uns estão de férias, outros não podem vir, mas, eventualmente, porque as pessoas são importantes para a conclusão do trabalho. Talvez isso possa estar no atravessamento, quer dizer, porque talvez seja uma questão relacionada com as pessoas e seus comprometimentos, éum contrato que a gente vive no mar das relaçôes. Algumas pessoas deveriam 
ter refeito um contrato de participação amiúde, ao longo do tempo, náo queria que a gente fosse percebendo que as coisas foram esvaziando.

Ao mesmo tempo, a discussão sobre os 'atravessamentos' foi revelando as condiçôes de trabalho que limitaram a participação.

Eu entendo que possa de alguma forma atrapalhar um pouco a dinâmica grupal, é alguém que deveria estar ali, mas tem os atravessamentos e condiçóes muito individuais que a gente náo pode fazer nada. Eu queria ter vindo a mais encontros, mas a gente fica tão cansada, tão sem energia - Ai, não quero mais saber do hospital - sabe assim? - Acho também que é um pouco da cultura do cotidiano; na semana retrasada também teve a chuva. Os imprevistos... sempre aconteciam. Eu pedia formalmente a liberação para eu repor aquela hora em outro dia, e acontecia algum imprevisto na enfermaria, no ambulatório. Trabalhar em dois lugares é difícil, em dois lugares que você não tem acesso à internet-acesso zero. Me via às 6 horas da tarde, tinha terminado de atender todo mundo, olhava para o teto esperando dar a hora, e sabendo que estava acontecendo um chat que eu poderia estar participando, e eu não tinha um acesso. Nenhum dos dois trabalhos onde eu estou tem acesso. Eu acho que seria legal para pesquisa própria dos profissionais; a gente tem essa demanda de pesquisa, de estar lendo, não é?

\subsubsection{Síntese das ideias centrais sob a perspectiva das participantes.}

\subsubsection{O processo dialógico}

O diálogo produzido durante a comunidade de prática é valioso, pois o processo de escuta e troca fortalece a identidade profissional, que se constitui a partir da diferença, o que contribui para o senso de pertencimento, integraçáo e consciência/coesão grupal.

\subsubsection{Implicações teórico-práticas}

As experiências vividas na comunidade de prática afirmam possibilidades de aproximação entre o exercício acadêmico e a prática profissional, favorecendo para o autoconhecimento e o crescimento do profissional, e sua valorização da profissão.

\subsubsection{O processo reflexivo}

A comunidade de prática possibilita refletir sobre os caminhos que foram e estão sendo construídos na prática profissional do terapeuta ocupacional, por meio da escuta das experiências clínicas que um profissional faz do outro.

\subsubsection{O processo participativo}

A avaliação das participantes sobre sua própria participação na comunidade de prática expressa as diferenças em relação à satisfação de suas expectativas, ao compromisso assumido e aos limites das condiçôes de trabalho.

\section{$3.2 \mathrm{O}$ processo reflexivo e dialógico de uma comunidade de prática segundo as pesquisadoras}

A análise do processo vivido pela comunidade, realizada pelos pesquisadores, apontou que os participantes usaram seus encontros para desabafo, compartilhamento, diálogo e reflexão sobre sua prática cotidiana. O processo reflexivo podia tanto se limitar a descrição e análise do raciocínio clínico por elas utilizado nas várias situaçóes de atendimento, bem como assumir um caráter mais crítico, remetendo às relaçóes de poder ou às condiçóes de trabalho no hospital. A reflexão conceitual e epistemológica apareceu em algumas discussões, mas de forma restrita.

Entretanto, uma característica marcante no processo reflexivo foi o uso frequente da narrativa clínica para a exemplificação da produção de cuidado no âmbito hospitalar, o que revelou uma prática com nuances e variáveis. Essa questão apareceu também em pesquisa anterior (GALHEIGO; TESSUTO, 2010), em que se constatou que a questão não estava no contar a prática, mas no 'refletir em voz alta', conceituando e estabelecendo um argumento formal. Na pesquisa em questáo, nas falas das entrevistadas, era comum que elas buscassem, em um momento de dificuldade, explicar por exemplos, contando uma história que aconteceu, apresentando o caso de algum paciente. Essa tendência vem sendo discutida por alguns autores como uma realidade presente na terapia ocupacional. Wilding e Whiteford (2007), que realizaram pesquisa com terapeutas ocupacionais em hospitais da Austrália, também constataram a dificuldade de se refletir sobre a prática da terapia ocupacional. Buscando entender como acontece a articulação entre os conflitos da construção paradigmática do trabalho e a prática cotidiana, as autoras se depararam com um tipo de narrativa oral, que se assemelha à encontrada nesta pesquisa.

Mattingly (1998), ao realizar estudo etnográfico sobre terapeutas ocupacionais em um hospital, 
se deparou com essa característica marcante do raciocínio clínico desses profissionais, concluindo que os terapeutas ocupacionais não utilizam as histórias apenas para obterem uma melhor orientação sobre seu trabalho, mas também para "[...] persuadir outras pessoas relevantes a vê-los como atores em tipos particulares de enredos terapêuticos" (MATTINGLY, 1998, p. 6).

Assim, o processo reflexivo e dialógico não se deu de forma focalizada, isto é, a temática sugerida para cada grupo presencial não era esgotada no próprio encontro. Ao contrário, havia um ir e vir nos temas e uma tendência a explorar as temáticas a partir da complexidade nelas implicada. Tendo em vista a perspectiva de Morin (2001) de que "complexo" remete ao termo complexus - que significa que tudo é tecido junto, interconectado -, pode-se inferir que as participantes buscaram refletir o processo de cuidado em sua complexidade. Assim, para dar um exemplo, na discussão sobre avaliação, apareciam questôes sobre a intervenção propriamente dita bem como sobre o desconhecimento da equipe acerca da terapia ocupacional ou sobre a fragilidade da rede de serviços. Outra característica importante é que as discussôes, em vários momentos, apresentaram um movimento em espiral, isto é, os temas retornavam à mesa de discussóes mais adiante no mesmo encontro presencial ou em algum outro grupo, mas com um grau de elaboração maior.

Esse recurso - a narrativa - também acontecia como uma forma de os participantes indicarem como refletem durante sua ação profissional - um processo que Schön (1987) nomeia de reflexão-durante-a-ação (reflection-in-action). Outros processos reflexivos foram também utilizados durante a comunidade, tais como a reflexáo intencional - que examina a ação a partir da experiência pessoal e da prática profissional - e a crítica - que se reporta ao significado socialmente negociado da atuação profissional em seus processos intersubjetivos, discursivos e de poder (KINSELLA, 2012). Entretanto, uma análise mais aprofundada dos processos reflexivos utilizados na comunidade extrapola os limites deste artigo e será oportunamente apresentada em trabalhos futuros.

Em relação ao processo participativo, é importante retomar que a comunidade de prática, tal como estudada por Wenger (1998), é, em geral, espontânea. Ao usar esta metodologia para a pesquisa e, assim, cultivar uma comunidade de prática, alguns desafios iniciais foram encontrados, a saber: realizar um convite que fizesse sentido para os possíveis participantes; promover interaçôes face a face atraentes; facilitar o vínculo entre os participantes, e acompanhar o processo de pertencimento à comunidade, já que o objetivo era estudar cooperação, participação, aprendizagem e troca de conhecimento.

O grupo apresentou diferentes níveis de engajamento, corroborando o apresentado na literatura (WENGER, 1998) de que as comunidades de prática geralmente apresentam participantes centrais e periféricos. Assim, a continuidade da pesquisa e sua chegada a termo dependeram tanto do engajamento desses participantes centrais como de estratégias de motivação, como promoção de oficinas com outros terapeutas ocupacionais que são referência no campo.

A apresentação de trabalhos sobre o levantamento de necessidades de pessoas hospitalizadas em Conferência Internacional $\left(9^{\circ}\right.$ Congresso Europeu de terapia ocupacional - COTEC) também foi fator essencial para a coesão da comunidade (BRAGA et al., 2012; GALHEIGO et al., 2012). A preparação dos trabalhos favoreceu a cooperação grupal e a corresponsabilização pelo processo vivido na comunidade, favorecendo a compreensão do 'agir' no processo da pesquisa-ação. Entretanto, foi desafiador para as participantes assumir seu papel de produtoras de conhecimento, reservando e valorando essa funçáo, na maior parte das vezes, como de responsabilidade e competência acadêmicas.

Várias barreiras ficaram evidentes no processo de organizaçáo de uma comunidade de prática. Desenvolvê-la demandava tempo e cooperação dos participantes, e a carência de terapeutas ocupacionais nos serviços e a significativa carga de trabalho diário foram obstáculos ao engajamento na comunidade. Assim, investir na participação em projetos após o horário de trabalho significava uma sobrecarga de trabalho ainda maior.

Ademais, há de se mencionar que há questôes de gênero importantes a serem consideradas, envolvendo o cuidado de filhos e as atividades domésticas, fato que fez com que duas convidadas desistissem de participar, após terem inicialmente aceito. A intensidade da vida urbana nas grandes metrópoles é também um fator desencorajador, principalmente contando o tempo de deslocamento, as dificuldades de transporte público, o custo e a falta de vagas para estacionamento, o enfrentamento de chuvas tropicais, dentre outros.

\section{Conclusão}

O desenvolvimento de uma comunidade de prática mostrou sua eficácia para a diminuição do isolamento entre profissionais e para a criaçáo de novas redes de colaboração profissional. Esta estratégia também possibilitou o fomento da discussão de temas relevantes e um aprofundamento do conhecimento 
da prática profissional, possibilitando o protagonismo das participantes na construçáo do conhecimento da profissão.

A experiência apontou a importância da comunicaçáo direta como a principal forma de trocas profissionais neste grupo, evidenciada pela preferência pela participação dos grupos presenciais e também pela maior adesão aos recursos que possibilitavam comunicação em tempo real, mesmo que por meio virtual (chat). Ficou clara a manifestação de interesse da continuidade pela experiência, isto é, na manutenção da comunidade de prática para além da fase de pesquisa, embora a manutençáo regular dos encontros presenciais pareça remota neste momento. Vale ressaltar, no entanto, que, mesmo após um ano da conclusão dos trabalhos, a comunidade ainda é acionada por alguns de seus participantes centrais, para a produção de trabalhos para eventos profissionais.

Há de se discutir as condiçôes reais de trabalho profissional e de deslocamento urbano, que se mostraram por vezes impeditivas ou, no mínimo, tornaram mais difícil a participaçáo efetiva nos grupos de discussão presenciais e virtuais.

A experiência deste grupo mostrou que a comunidade de prática é uma estratégia para a construção compartilhada de saberes e que sua implementaçáo no campo da terapia ocupacional pode engendrar impactos significativos para o fomento da reflexão, o desenvolvimento da pesquisa e a produção de conhecimento, bem como contribuir para o aprimoramento da prática profissional do terapeuta ocupacional.

\section{Agradecimentos}

Agradecemos à Dr.a Lilian Magalhães e à Dr. ${ }^{a}$ Elizabeth Anne Kinsella, pela colaboração na discussão dos resultados da pesquisa, e, em particular, à Dr.a Lilian Magalhães, pela leitura criteriosa deste texto.

\section{Referências}

ASSOCIAÇÃO CIENTÍFICA DE TERAPIA OCUPACIONAL EM CONTEXTOS HOSPITALARES E CUIDADOS PALIATIVOS - ATOHOSP. Estatuto social. Disponível em: <http://atohosp.com.br/estatuto. html>. Acesso em: 16 jul. 2013.

BOURDIEU, P.; WACQUANT, L. An invitation to reflexive sociology. Chicago: The University of Chicago Press, 1992.

BRAGA, C. P. et al. Similarities and diversities in occupational therapy assessment of hospitalized children and adolescents. In: COTEC CONGRESS OF OCCUPATIONAL THERAPY, 9., 2012, Estocolmo. Abstracts
Database. Estocolmo: COTEC/Swedish Association of Occupational Therapists, 2012. p. 1.

CHAU, T.; MOGHIMI, S.; POPOVIC, M. R. Knowledge translation in rehabilitation engineering research and development: a knowledge ecosystem framework. Archives of Physical Medicine and Rehabilitation, Chicago, v. 94, n. 1, p. S9-S19, 2013. Suplemento. http://dx.doi. org/10.1016/j.apmr.2012.07.032. PMid:23260777.

CRAMM, H.; WHITE, C.; KRUPA, T. From periphery to player: strategically positioning occupational therapy within the knowledge translation landscape. The American Journal of Occupational Therapy, Rockville, v. 67, n. 1, p. 119-125, 2013. http://dx.doi.org/10.5014/ ajot.2013.005678. PMid:23245790.

DERDALL, M.; MULHOLLAND, S.; BROWN, C. Evaluating students' use of web-based communication during practice placements. British Journal of Occupational Therapy, London, v. 73 , n. 10, p. 457$460, \quad 2010$. http://dx.doi.org/10.4276/03080221 0X12865330218221.

GALHEIGO, S. M. Práticas hospitalares em terapia ocupacional: um estudo sobre a consolidação do campo no Estado de São Paulo. São Paulo: Mimeo, 2006. Projeto de pesquisa desenvolvido com o apoio do Edital MCT/CNPq 02/2006 - Universal sob o processo ${ }^{\circ}$ 473769/2006-9.

GALHEIGO, S. M. Refletindo sobre as práticas hospitalares da terapia ocupacional: um estudo das perspectivas de terapeutas ocupacionais no Estado de São Paulo. In: CONGRESSO BRASILEIRO DE TERAPIA OCUPACIONAL, 11., 2009, São Paulo. Anais... Revista de Terapia Ocupacional da USP, São Paulo, v. 1, p. 1-1, 2009.

GALHEIGO, S. M.; ANTUNES, J. R. A caracterização da produçáo bibliográfica nas práticas hospitalares em terapia ocupacional no Brasil: uma revisão da literatura de 1990 a 2007. Revista de Terapia Ocupacional da USP, Sáo Paulo, v. 19, n. 2, p. 91-99, 2008.

GALHEIGO, S. M.; TESSUTO, L. A. Trajetórias, percepçōes e inquietaçôes de terapeutas ocupacionais do Estado de São Paulo no âmbito das práticas da terapia ocupacional no hospital. Revista de Terapia Ocupacional da USP, São Paulo, v. 21, n. 1, p. 23-32, 2010.

GALHEIGO, S. M. et al. Assessing the needs of hospitalized children and adolescents: dialogues within a community of practice. In: CONGRESS OF OCCUPATIONAL THERAPY, 9., 2012, Estocolmo. Abstracts Database. Estocolmo: COTEC/Swedish Association of Occupational Therapists, 2012.

GALVIN, D.; WILDING, C.; WHITEFORD, G. Utopian visions/dystopian realities: exploring practice and taking action to enable human rights and occupational justice in a hospital context. Australian Occupational Therapy Journal, Melbourne, v. 58, n. 5, p. 378-385, 2011. http://dx.doi.org/10.1111/j.14401630.2011.00967.x. PMid:21957923.

HOFFMANN, T.; DESHA, L.; VERRALL, K. Evaluating an online occupational therapy community of 
practice and its role in supporting occupational therapy practice. Australian Occupational Therapy Journal, Melbourne, v. 58, n. 5, p. 337-345, 2011. http:// dx.doi.org/10.1111/j.1440-1630.2011.00954.x. PMid:21957918.

KEMMIS, S. Knowing practice: searching for saliences. Pedagogy, Culture \& Society, Sheffield, v. 13, n. 3, p. 391-426, 2005. http://dx.doi.org/10.1080/14681 360500200235 .

KINSELLA, E. A. Practitioner reflection and judgement as phronesis. In: KINSELLA, E. A.; PITMAN, A. Phronesis as professional knowledge. Rotterdam: Sense Publishers, 2012. p. 35-52.

KINSELLA, E. A.; WHITEFORD, G. E. Knowledge generation and utilisation in occupational therapy: towards epistemic reflexivity. Australian Occupational Therapy Journal, Melbourne, v. 56, n. 4, p. 249-258, 2009. http://dx.doi.org/10.1111/j.1440-1630.2007.00726.x. PMid:20854525.

LEFEVRE, A. M. C.; CRESTANA, M. F; CORNETTA, V. K. A utilização da metodologia do discurso do sujeito coletivo na avaliação qualitativa dos cursos de especialização "Capacitação e Desenvolvimento de Recursos Humanos em Saúde - CADRHU”, São Paulo - 2002. Saúde e Sociedade, São Paulo, v. 12, n. 2, p. 68-75, 2003. http://dx.doi.org/10.1590/S010412902003000200007.

LIDSKOG, M.; LÖFMARK, A.; AHLSTRÖM, G. Learning through participating on an interprofessional training ward. Journal of Interprofessional Care, Abingdon, v. 23, n. 5, p. 486-497, 2009. http://dx.doi. org/10.1080/13561820902921878. PMid:19657936.

LIMA, E. M. F. A. Identidade e complexidade: composiçôes no campo da terapia ocupacional. Revista de Terapia Ocupacional da USP, São Paulo, v. 10, n. 1, p. 37-42, 1999.

LIMA, E. M. F. A. Desejando a diferença: reflexões sobre as relaçóes entre os terapeutas ocupacionais e as populaçôes tradicionalmente atendidas por estes profissionais. Revista de Terapia Ocupacional da USP, Sáo Paulo, v. 14, n. 1, p. 64-71, 2003.
MATTINGLY, C. F. Healing dramas and clinical plots: the narrative structure of experience. Cambridge: Cambridge University Press, 1998.

MINAYO, M. C. Hermenêutica-dialética como caminho do pensamento social. In: MINAYO, M. C.; DESLANDES, S. Caminhos do pensamento: epistemologia e método. Rio de Janeiro: Fiocruz, 2002. p. 83-108.

MORIN, E. Os Sete saberes necessários à educação no futuro. São Paulo: Cortez, 2001.

SCHÖN, D. Educating the reflective practitioner. San Francisco: Jossey-Bass, 1987.

THIOLLENT, M. Notas para o debate sobre pesquisa-ação. In: BRANDÁO, C. R. Repensando a pesquisa participante. São Paulo: Brasiliense, 1987. p. 82-103.

WENGER, E. Communities of practice: learning, meaning and identity. Cambridge: Cambridge University Press, 1998.

WENGER, E.; MCDERMONT, R.; SNYDER, W. Cultivating communities of practice. Boston: Harvard Business School Press, 2002.

WILDING, C.; CURTIN, M.; WHITEFORD, G. Enhancing occupational therapists' confidence and professional development through a community of practice scholars. Australian Occupational Therapy Journal, Melbourne, v. 59, n. 4, p. 312-318, 2012. http://dx.doi.org/10.1111/j.1440-1630.2012.01031.x. PMid:22934904.

WILDING, C.; WHITEFORD, G. Occupation and occupational therapy: knowledge paradigms and everyday practice. Australian Occupational Therapy Journal, Melbourne, v. 54, n. 3, p. 185-193, 2007. http:// dx.doi.org/10.1111/j.1440-1630.2006.00621.x.

WILDING, C.; WHITEFORD, G. From practice to praxis: reconnecting moral vision with philosophical underpinnings. British Journal of Occupational Therapy, London, v. 72, n. 10, p. 434-441, 2009. http://dx.doi. org/10.1177/030802260907201004.

WIMPENNY, K. et al. Implementing the model of human occupation across a mental health occupational therapy service: Communities of practice and a participatory change process. British Journal of Occupational Therapy, London, v. 73, n. 11, p. 507-516, 2010. http:// dx.doi.org/10.4276/030802210X12892992239152.

\title{
Contribuição dos Autores
}

Por se tratar de uma pesquisa-ação, todos os autores participaram da produção do conteúdo do artigo. Sandra Maria Galheigo e Claudia Pellegrini Braga realizaram a análise de conteúdo do material e junto com Rosa Maria de Araújo Mitre escreveram a versão final. Todos os autores aprovaram a versão final do texto.

\section{Fonte de Financiamento}

\author{
PIBIC/CNPq e FAPESP.
}

\section{Notas}

${ }^{1}$ Importante destacar que não foi nossa intenção utilizar a técnica do Sujeito do Discurso Coletivo (LEFEVRE; CRESTANA; CORNETTA, 2003), embora haja alguma semelhança entre esta e a forma que utilizamos para apresentar os resultados. 